\title{
PENGARUH BOPO, CAR DAN LDR TERHADAP PROFITABILITAS PERBANKAN
}

\section{Aditya Permana Magdalena ${ }^{1}$ Nesti Hapsari $^{2}$}

Article history:

Submitted:

21 Mei 2021

Revised:

13 Juni 2021

Accepted:

15 Juni 2021

Keywords:

BOPO;

CAR;

$L D R$;

$R O A$.

Kata Kunci:

BOPO;

CAR;

LDR;

ROA.

\section{Koresponding:}

Fakultas Ekonomi, Universitas

Singaperbangsa Karawang, Jawa

Barat, Indonesia

Email:

magdalenatya03@gmail.com

\section{Abstract}

Banking is a financial industry that is closely related to people's daily activities. This study aimed to determine the effect of Operasioal Cost to Operating Income, Capital Adequacy Ratio, and Loan to Deposit Ratio on Return on Assets in banking companies listed in Indonesia Stock Exchange 2015-2019 period. The method used in this research is a quantitative research using multiple linear regression analysis techniques. Sample selection using a purposive sampling technique. The partial test results show that BOPO has a negative and significant effect on ROA, CAR has no effect on ROA and LDR has no effect on ROA. Based on the results that the company's profitability is not always influenced by capital and credit and this research can be used as a support in decision making for investors in investing.

\section{Abstrak}

Perbankan merupakan sebuah industri keuangan yang memiliki keterkaitan dengan aktivitas masyarakat sehari-hari. Penelitian ini ditujukan untuk mengetahui pengaruh Biaya Operasioal terhadap Pendapatan Operasional, Capital Adequacy Ratio dan Loan to Deposit Ratio terhadap Return On Asset pada perusahaan perbankan yang terdaftar di Bursa Efek Indonesia periode 2015-2019. Metode yang digunakan dalam penelitian ini adalah penelitian kuantitatif dengan menggunakan teknik analisis regresi liner berganda. Pemilihan sampel menggunakan teknik purposive sampling. Hasil uji parsial menunjukkan bahwa BOPO memiliki pengaruh negatif dan signifikan terhadap ROA, CAR tidak memiliki pengaruh terhadap ROA dan LDR tidak memiliki pengaruh terhadap ROA. Berdasarkan hasil penelitian didapatkan bahwa profitabilitas perusahaan tidak selalu dipengaruhi oleh faktor modal dan kredit dan penelitian ini dapat digunakan sebagai pendukung dalam pengambilan keputusan bagi investor dalam berinvestasi.

Fakultas Ekonomi, Universitas Singaperbangsa Karawang, Jawa Barat, Indonesia ${ }^{2}$

Email: nestihapsariemsi@gmail.com 


\section{PENDAHULUAN}

Perbankan merupakan salah satu industri keuangan yang sudah sangat dikenal oleh masyarakat, kegiatan sehari-hari masyarakat tidak lepas dari peran perbankan. Dalam perekonomian nasional, bank merupakan jantung ekonomi dikarenakan bank mengalirkan kembali uang yang diterima untuk diedarkan ke sistem perekonomian guna menjalankan kegiatan perekonomian (Wijaya \& Tiyas, 2016). Perbankan menjadi sebuah media dalam menghimpun dana masyarakat baik itu dalam kegiatan sebuah bisnis antara perusahaan ataupun masyarakat. Perbankan adalah sebuah lembaga yang mengemban peran sebagai penghubung antara pihak yang memiliki anggaran lebih dengan pihak yang membutuhkan anggaran serta mengemban fungsi dalam pelancaran lalu lintas pembayaran (PSAK 31; Ikatan Akuntan Indonesia, 2012). Bagi masyarakat perbankan adalah tempat untuk menyimpan sejumlah uang yang dimiliki dengan adanya jaminan sehingga masyarakat mermiliki rasa aman untuk menyimpan uangnya di bank. Dengan adanya perbankan masyarakat merasakan dampak yang baik. Namun seiring berjalannya waktu perbankan perlu mengalami berbagai krisis. Dalam menghadapi krisis tersebut perbankan perlu menyeimbangkan usaha dan kemampuannya dengan situasi yang sedang dihadapi. Misalnya pada tahun 1998, kejadian krisis ekonomi yang diakibatkan oleh nilai tukar mata uang yang mengalami penurunan di beberapa negara Asia termasuk Indonesia. Pada tahun 2008 Indonesia mengalami krisis ekonomi yang diakibatkan karena naiknya harga minyak dunia yang disertai dengan penurunan nilai tukar yang terjadi dibeberapa negara Asia secara mendadak. Kemudian di tahun 2020, krisis ekonomi yang kembali melanda Indonesia. Defisit fiskal yang terjadi sejak tahun 2014 menyebabkan beban hutang negara semakin membesar. Krisis ekonomi di tahun 2020 didorong pula oleh adanya defisit transaksi berjalan serta defisit perdagangan sehingga memengaruhi harga saham di pasar modal dan nilai tukar rupiah yang kemudian diiringi dengan adanya pandemi Covid-19 yang menimpa seluruh negara di dunia sehingga menyebabkan krisis ini semakin sulit.

Krisis ekonomi yang dialami oleh masyarakat tentu memberikan dampak terhadap likuiditas perbankan. Maka dari itu perbankan perlu memiliki ketanggapan dan kesiapan dalam menjalani bisnisnya agar dapat bertahan serta menghadapi berbagai tantangan dalam dunia ekonomi. Dalam meredam dampak pandemi Covid-19, perbankan menjadi salah satu andalan masyarakat. Masyakarat mengajukan permohonan keringanan pembiayaan bank kepada pemerintah agar dapat meringankan beban selama pandemi berlangsung. Dalam menjalankan kegiatannya, bank diharuskan mempunyai dana untuk diberikan kredit kepada masyarakat. Modal utama bank ditujukan untuk menutupi kemungkinan terjadi kerugian tidak terduga serta dijadikan cadangan jika sewaktu-waktu terjadi krisis perbankan (Ikatan Bankir Indonesia, 2016).

Piter Abdullah seorang direktur riset ekonom Center of Reform On Economics mengatakan, "Keadaaan sektor perbankan 
saat ini masih relatif yang terlefleksikan dari rasio kecukupan modal (CAR) dan rasio kredit macet (NPL) yang masih berada dilevel aman. Keadaan NPL masih relatif terjaga sehingga mengakibatkan CAR bank juga terjaga. LDR perbankan nasional saat ini berada pada level $87.76 \%$ dan mengalami penurunan dari bulan sebelumnya yakni $88,64 \%$. Artinya likuiditas bank masih sangat aman. Peningkatan NPL masih berada pada range yang masih sangat aman, yaitu dibawah 5\%. Sementara itu, CAR perbankan nasioal mengalami kenaikan menjadi 23,1\% pada Juli 2020 jika dibandingkan dengan tahun sebelumnya yaitu $22,59 \%$ (Ramli, 2020).

Nilai CAR, BOPO dan LDR merupakan cerminan dari kinerja perbankan yang ditunjukan dalam angka-angka rasio. Kemampuan perbankan tidak terlepas dari keuntungan yang akan dihasilkan. Dalam analisis keuangan, rasio profitabilitas merupakan alat ukur yang sangat tepat untuk menilai kemampuan kinerja suatu bank. Profitabilitas dapat memberikan gambaran terkait efesiensi manajemen suatu perusahaan (Kasmir, 2014:196). Rasio profitabilitas meliputi dua aspek rasio, yaitu return on asset dan return on equity. Dalam Peraturan Bank Indonesia No. 13 tahun 2011 perihal Penilaian Tingkat Kesehatan Bank Umum, dinyatakan bahwa rasio return on assets (ROA) merupakan parameter utama yang digunakan untuk menentukan tingkat kesehatan bank. Suatu bank yang mampu beroperasi secara efektif dan efisien tentu memiliki profitabilitas yang tinggi, sehingga bank berpeluang untuk melakukan perluasan usaha (Warsa \& Mustanda, 2016). Menurut
Munawir (2014:86), rasio profitabilitas atau rentabilitas merupakan rasio yang menunjukkan bagaimana perusahaan mampu dalam menghasilkan laba pada periode tertentu. Berikut adalah grafik pertumbuhan rata-rata ROA perusahaan perbankan yang terjadi pada tahun 2015-2019.

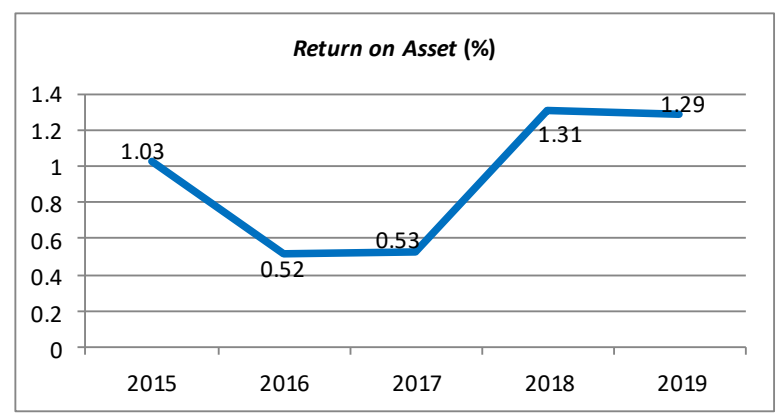

Sumber : Laporan Tahunan Perbankan, data diolah peneliti (2021)

Gambar 1.

Grafik Pertumbuhan Rata-Rata ROA Perbankan yang Terdaftar di BEI Periode 2015-2019

Pada tahun 2015 rata-rata ROA perbankan berada pada angka $1,03 \%$ lalu mengalami penurunan di tahun 2016 menjadi 0,52\%. Kemudian pada tahun 2017 ROA mengalami peningkatan ke angka $0,53 \%$ lalu meningkat kembali menjadi $1,31 \%$ di tahun 2018. Hal ini menandakan bahwa manajemen mulai memperhatikan pengelolaan dananya untuk menghasilkan laba ditahun tersebut. Pada tahun 2019 ROA mengalami penurunan kembali menjadi sebesar $0,02 \%$ menjadi $1.29 \%$, dimana hal ini menggambarkan kemampuan manajemen perbankan dalam mengelola dananya masih kurang baik. Penurunan profitabilitas perbankan dapat disebabkan oleh beberapa faktor seperti risiko operasional perusahaan, kecukupan modal perusahaan dan likuidasi perusahaan. 
Tabel 1 adalah data pertumbuhan ratarata BOPO, CAR dan LDR pada perusahaan perbankan yang terdaftar di Bursa Efek Indonesia yang terjadi pada tahun 2015-2019.

Tabel 1.

Rata-Rata BOPO, CAR dan LDR Perbankan yang Terdaftar di BEI Periode 2015-2019

\begin{tabular}{cccc}
\hline Tahun & BOPO $(\boldsymbol{\%})$ & CAR $(\boldsymbol{\%})$ & LDR $(\boldsymbol{\%})$ \\
\hline $\mathbf{2 0 1 5}$ & 89.33 & 18.98 & 86.14 \\
\hline $\mathbf{2 0 1 6}$ & 98.84 & 21.45 & 85.32 \\
\hline $\mathbf{2 0 1 7}$ & 95.87 & 22.04 & 81.78 \\
\hline $\mathbf{2 0 1 8}$ & 90.23 & 22.64 & 87.45 \\
\hline $\mathbf{2 0 1 9}$ & 95.48 & 25.38 & 89.65 \\
\hline
\end{tabular}

Sumber : Laporan Tahunan Perbankan, data diolah peneliti (2021)

$2019 \begin{gathered}\text { Rata-rata BOPO pada tahun 2015- } \\ \text { menunjukan tingkat efisiensi }\end{gathered}$ perusahaan mengalami fluktuasi tiap tahunnya. Pada tahun 2015 rata-rata BOPO perbankan adalah 89,33\%, angka ini merupakan BOPO terendah selama periode penelitian. Berdasarkan angka tersebut dapat digambarkan kemampuan efeisiensi perusahaan pada tahun tersebut adalah yang paling baik diantara tahun-tahun berikutnya. Rata-rata BOPO tertinggi terjadi pada tahun 2016 dan telah melampaui batas aman efisiensi operasional perusahaan. Dalam surat edaran Bank Indonesia No.13 tahun 2011 perihal Sistem Penilaian Tingkat Kesehatan Bank Umum menjelaskan peraturan batas aman rasio BOPO megalami perubahan dari 94\% menjadi 97\%. Angka pada tabel menunjukkan bahwa nilai BOPO masih cukup tinggi sehingga perbankan perlu memperhatikan kembali tingkat efisien operasional perusahaannya agar dapat meningkatkan kinerja perusahaan dan mendapat laba yang tinggi. Dalam kegiatan perbankan, risiko operasional berpengaruh terhadap kegiatan operasional bank yang disebabkan oleh proses internal yang tidak berfungsi, human error, sistem yang buruk serta kejadian eksternal (Ikatan Bankir Indonesia, 2016). Tingkat efisiensi bank dapat diukur menggunakan rasio BOPO. Pada saat bank mampu menekan biaya operasional yang digunakan untuk mengelola kegiatan usahanya, maka pada saat itu bank akan memperoleh labanya (Ikatan Bankir Indonesia, 2016). Jika efisiensi bank dalam menjalankan aktivitasnya semakin baik maka BOPO yang dimiliki pun akan semakin kecil (Hartini, 2016). Dalam penelitian yang dilakukan oleh Pradnyawati \& Widhiastuti (2020) dinyatakan bahwa BOPO memiliki pengaruh negatif dan signifikan terhadap profitabilitas. Hal ini didukung oleh Dewi (2018); Rusmini \& Adiandari (2020) yang juga membuktikan dalam hasil penelitiannya bahwa BOPO memiliki pengaruh negatif dan signifikan terhadap profitabilitas. Namun pernyataan ini tidak sejalan dengan hasil penelitian yang dilakukan Marwansyah \& Setyaningsih (2018) yang menyatakan bahwa BOPO tidak memiliki pengaruh terhadap profitabilitas.

Kemampuan permodalan bank yang terefleksikan oleh capital adequacy ratio (CAR) pada tahun 2015 berada pada angka $18,98 \%$ kemudian mengalami peningkatan selama empat tahun berturut-turut dan nilai CAR tertinggi terjadi pada tahun 2019 yaitu sebesar 25,38\%. Dalam POJK Nomor 15 tahun 2017 perihal Penetapan Status dan Tindak Lanjut Pengawasan Bank Umum, disebutkan bahwa batas minimum CAR 
adalah sama dengan atau dibawah $8 \%$. Nilai CAR pada tahun 2015-2019 yang berada diatas angka 8 menunjukkan bahwa manajemen telah melakukan pengelolaan dalam menyediakan modal minimum bank dengan sangat baik. Semakin tinggi rasio kecukupan modal maka kepercayaan masyarakat terhadap bank akan semakin meningkat serta deposan dapat terlindungi, sehingga pendapatan bank ikut mengalmi peningkatan (Febrianti \& Ladinus, 2019). Dalam penelitian yang dilakukan oleh Nuryanto dkk., (2020) CAR dikatakan memiliki pengaruh positif tidak signifikan terhadap profitabilitas. Pernyataan ini didukung oleh Korri \& Baskara (2019); Anggari \& Dana (2020) yang menyatakan hal sama dalam penelitiannya. Namun berbeda dengan hasil penelitian yang dilakukan oleh Pandoyo \& Samsudin (2020) yang menyatakan bahwa CAR tidak memiliki pengaruh terhadap profitabilitas. Pernyataan ini didukung dengan penelitian Marwansyah \& Setyaningsih (2018); Azmy dkk., (2019) yang menyatakan bahwa CAR tidak memiliki pengaruh terhadap profitabilitas.

Nilai LDR pada tahun 2015-2019 mengalami fluktuasi. Nilai LDR terendah terjadi di tahun 2017 yakni sebesar 81,78\% dan nilai LDR tertinggi terjadi di tahun 2019 yakni sebesar 89,65\%. Dalam surat edaran peraturan BI No.17 tahun 2015 perihal Perubahan atas Peraturan Bank Indonesia No.15 tahun 2013, disebutkan batas aman LDR (Loan to Deposit Ratio) yang selanjutnya berubah menjadi LFR (Loan to Funding Ratio) adalah sebesar 92\% dengan batas bawah sebesar 78\%. Nilai LDR yang terjadi pada tahun 2015-2019 dapat dikatakan sangat baik karena memenuhi kriteria dalam batas aman yang telah disebutkan dalam peraturan. Menurut Munawir (2014:31) likuiditas adalah kewajiban keuangan yang mampu dihadapi oleh perusahaan segera atau pada saat ditagih. LDR merupakan alat ukur utama yang digunakan dalam mengetahui besar jumlah penyaluran kredit yang dibandingkan dengan banyaknya modal sendiri dan dana masyarakat (Kasmir, 2014:225). Apabila volume kredit yang disalurkan semakin tinggi maka profitabilitas akan semakin meningkat oleh karena pendapatan bank diperoleh melalui bunga kredit (Septiani \& Lestari, 2016). Pinasti \& Mustikawati (2018) dalam penelitiannya menyatakan bahwa LDR berpengaruh terhadap profitabilitas. Penelitian ini didukung oleh Peling \& Sedana (2018) yang menyatakan hal sama dalam penelitiannya. Namun berbeda dengan hasil penelitian yang dilakukan oleh Pandoyo \& Samsudin (2020) yang menyatakan bahwa LDR tidak berpengaruh terhadap profitabilitas. Pendapat ini sejalan dengan penelitian yang dilakukan oleh Fajari \& Sunarto (2017) yang juga menyatakan bahwa LDR tidak berpengaruh terhadap profitabilitas.

Berdasarkan pemaparan yang telah dijelaskan terhadap CAR, BOPO, LDR serta ROA yang berkaitan dengan fenomena yang terjadi dan adanya research gap pada penelitian sebelumnya. Maka dari itu, peneliti terdorong untuk melakukan penelitian kembali mengenai "Pengaruh BOPO, CAR dan LDR terhadap Profitabilitas Perbankan", adapun peneliti mengajukan hipotesis sebagai berikut; $\mathrm{H}_{1}$ : terdapat pengaruh $\mathrm{BOPO}$ terhadap profitabilitas, $\mathrm{H}_{2}$ : terdapat pengaruh 
CAR terhadap profitabilitas, $\mathrm{H}_{3}$ :terhadap pengaruh LDR terhadap Profitabilitas.

\section{METODE PENELITIAN}

Penelitian ini menggunakan pendekatan kuantitatif deskriptif, yaitu pendekatan untuk mempelajari tata cara dalam mengumpulkan, menyusun dan menyajikan ringkasan yang diteliti (Wijaya, 2013). Tujuan penggunaan pendekatan deskriptif yaitu untuk memperoleh kehadiran variabel tunggal, baik terdiri atas satu atau lebih variabel bebas tanpa membandingkan variabel itu sendiri serta untuk mengetahui variabel lainnya yang berhubungan (Sugiyono, 2017). Variabel yang digunakan dalam penelitian ini terdiri dari variabel dependen (Y) yaitu ROA dan variabel independen (X) yaitu BOPO, CAR dan LDR.

ROA (Return On Asset) adalah rasio yang berkaitan dengan potensi kentungan untuk mengukur kekuatan perusahaan dalam menghasilkan profit pada tingkat pendapatan, aset dan modal saham spefisik. ROA digunakan untuk menunjukkan presentase laba bersih yang diperoleh suatu perusahaan berkaitan dengan sumber daya yang dimiliki atau rata-rata jumlah aset. Untuk menghitung nilai ROA dapat menggunakan rumus :

ROA $=$ Laba Setelah Pajak/ Total

Asset x 100\%.

BOPO merupakan rasio yang digunakan untuk menilai tingkat efisiensi kinerja operasional suatu bank. BOPO merupakan rasio perbandingan antara nilai biaya operasional dengan pendapatan operasional, rasio BOPO yang semakin rendah menunjukkan bahwa kinerja manajemen bank tersebut semakin baik, hal ini menunjukkan pula bahwa manajemen bank telah mengaplikasikan sumber tenaga yang dimiliki dengan lebih efisien. Dalam mengukur nilai BOPO suatu bank, maka dapat digunakan rumus :

BOPO $=$ Total Beban Operasional $/$ Total

Pendapatan Operasional x 100\%..(2)

CAR (Capital Adequacy Ratio) adalah rasio yang digunakan untuk menghitung jumlah kecukupan modal minimum yang dimiliki perbankan pada saat menghadapi berbagai risiko kerugian yang dapat terjadi dikemudian hari. Risiko kerugian ini dapat berupa risiko kredit, risiko operasional dan risiko pasar. Nilai CAR didapat dari perbandingan modal dengan Aset Tertimbang Menurut Risiko (ATMR). Maka dari itu untuk menghitung CAR suatu bank dapat menggunakan rumus :

$\mathrm{CAR}=$ Modal $/$ ATMR $\times 100 \%$

LDR (Loan to Deposit Ratio) merupakan rasio yang menunjukkan seberapa besar kesanggupan suatu bank saat membayar kembali penarikan uang yang dilakukan deposan dengan mempercayakan kredit yang diberikan sebagai sumber likuiditasnya. Kredit yang digunakan merupakan jumlah kredit yang diberikan kepada pihak ketiga tidak termasuk bank lain yang dibagi dengan anggaran dari modal bank, dana pihak ketiga mencakup tabungan, giro dan deposito (tidak termasuk antar bank) dan surat berharga yang diterbitkan.

LDR $=$ Total Kredit yang diberikan/ Total

DPK x $100 \%$..

Jenis data pada penelitian ini menggunakan data sekunder dan sumber data yang digunakan merupakan angka rasio yang 
Pengaruh BOPO, CAR dan LDR Terhadap...

Aditya Permana Magdalena \& Nesti Hapsari

dinyatakan dalam laporan keuangan perusahaan. Pengumpulan data dilakukan melalui studi kepustakaan, pengumpulan dokumentasi dalam bentuk laporan tahunan perusahaan yang diterbitkan pada situs resmi perusahaan dan Bursa Efek Indonesia serta melakukan kajian literatur terhadap teori-teori yang relevan dan penelitian yang telah terpublikasi. Populasi yang digunakan dalam penelitian ini adalah perusahaan sektor perbankan yang telah go public atau terdaftar di Bursa Efek Indonesia dan sampel yang digunakan sebanyak 27 dari total populasi sebanyak 45 perusahaan berdasarkan seleksi terhadap kriteria tertentu yang peneliti tetapkan melalui metode purposive sampling. Adapun kriteria yang peneliti terapkan meliputi; (1) Merupakan perusahaan sub sektor perbankan yang terdaftar di BEI pada tahun 2015-2019, (2) Perusahaan sub sektor perbankan mempublikasikan laporan tahunan (annual report) secara berturut-turut pada tahun 2015-2019, (3) Perusahaan sub sektor perbankan memiliki kelengkapan data-data yang diperlukan pada penelitian.

Dalam penelitian ini peneliti melakukan pengujian hipotesis menggunakan analisis regresi linear berganda dengan alat bantu aplikasi perangkat lunak SPSS versi 21. Pengujian hipotesis yang ditunjukkan oleh model regresi harus melalui serangkaian uji asumsi klasik, yiatu uji normalitas data, uji multikolinieritas, uji autokolerasi dan uji heterokedastisitas sebelum dilakukan pengujian data lebih lanjut. Berikut merupakan persamaan model regresi yang digunakan dalam penelitian ini :

$\mathrm{Y}=\mathrm{a}_{0}+\mathrm{B}_{1} \mathrm{X}_{1}+\mathrm{B}_{2} \mathrm{X}_{2}+\mathrm{B}_{3} \mathrm{X}_{3}+\mathrm{e} \ldots \ldots$ (5)
Keterangan :

$\mathrm{Y} \quad$ : Return on Asset (ROA)

$\mathrm{X} 1$ : Efisiensi Operasional (BOPO)

$\mathrm{X} 2$ : Capital Adequacy Ratio (CAR)

X3 : Loan to Deposit Ratio (LDR)

e : error

\section{HASIL DAN PEMBAHASAN}

Analisis deskriptif merupakan analisis yang dilakukan pada data statistik dengan mendeskripsikan tanpa menciptakan kesimpulan yang berlaku untuk umum (Sanusi, 2011:95). Tujuan dilakukannya analisis deksriptif yaitu untuk menggambarkan dan menjelaskan variabel yang diteliti dalam bentuk pernyataan sesuai kebenarannya. Berikut adalah hasil analisis statistik deskriptif yang peneliti lakukan menggunakan alat bantu aplikasi perangkat lunak SPSS v.21.

Tabel 2.

Analisis statistik deskriptif variabel penelitian

\begin{tabular}{cccccc}
\hline \multicolumn{6}{c}{ Descriptive Statistics } \\
\hline & N & $\begin{array}{c}\text { Mini- } \\
\text { mum }\end{array}$ & $\begin{array}{c}\text { Maxi- } \\
\text { mum }\end{array}$ & Mean & $\begin{array}{c}\text { Std. } \\
\text { Deviation }\end{array}$ \\
\hline BOPO & 135 & 60.10 & 122.97 & 86.188 & 10.44881 \\
CAR & 135 & 10.52 & 45.85 & 21.332 & 5.87196 \\
LDR & 135 & 50.61 & 145.26 & 87.203 & 15.06285 \\
ROA & 135 & -3.39 & 3.53 & 1.335 & 1.12135 \\
Valid N & & & & & \\
(listwise) & 135 & & & & \\
\hline
\end{tabular}

Sumber : Hasil Pengolahan SPSS, Peneliti (2021)

Berdasarkan hasil analisis statistik deskriptif pada Tabel 2., diketahui jumlah keseluruhan data yang digunakan yaitu sebanyak 135 data. Nilai minimum BOPO adalah 60,10\%, angka ini berasal dari PT Bank Bumi Arta Tbk. dengan nilai rata-rata 
sebesar $86,18 \%$ dan nilai maksimum sebesar $122,97 \%$ yang berasal dari PT Bank Neo Commerce Tbk. Nilai standar deviasi BOPO adalah sebesar 10,44, karena nilai rata-rata BOPO berada diatas standar deviasinya maka dapat disimpulkan bahwa data menyebar dan normal.

Nilai minimum CAR sebesar $10,52 \%$ diperoleh dari PT Bank KB Bukopin Tbk. dengan nilai rata-rata $21,33 \%$ dan nilai maksimum $45,85 \%$ diperoleh PT Bank of India Indonesia Tbk. Standar deviasi CAR yaitu sebesar 5,87 dan angka ini berada dibawah nilai rata-rata CAR yang artinya data menyebar dan normal.

Nilai minimum LDR adalah 50,61\%, angka ini berasal dari PT Bank Capital Indonesia Tbk. dengan nilai rata-rata $87,20 \%$ dan nilai maksimum sebesar 145,26\% diperoleh PT Bank Woori Saudara Indonesia 1906 Tbk. Standar deviasi LDR adalah sebesar 15,06 dan angka ini berada dibawah nilai rata-rata LDR yang artinya data menyebar dan normal.

Nilai minimum ROA adalah sebesar 3,39\%, angka ini diperoleh dari PT bank of India Indonesia Tbk. dengan nilai rata-rata $1,33 \%$ dan nilai maksimum sebesar 3,53\% diperoleh dari PT Bank Mestika Dharma Tbk. Standar deviasi ROA sebesar 1,12 dan angka ini berada dibawah standar deviasinya, maka dapat disimpulkan data menyebar dan normal.

Pengujian normalitas dilakukan untuk mendeteksi apakah data yang akan diteliti layak digunakan dan berdistribusi normal yaitu dengan melihat pada nilai KolmogorovSmirnov. Apabila nilai Sig. (2-tailed) variabel $>0,05$, maka data tersebut berdistribusi normal dan penelitian dapat dilanjutkan, sebaliknya apabila nilai Sig. (2-tailed) variabel $<0,05$, maka data tidak berdistribusi normal sehingga penelitian tidak dapat dilanjutkan. Berikut adalah hasil uji normalitas pada variabel BOPO, CAR, LDR dan ROA yang akan diteliti.

Tabel 3.

Hasil Uji normalitas

\begin{tabular}{|c|c|c|c|c|}
\hline \multicolumn{5}{|c|}{ One-Sample Kolmogorov-Smirnov Test } \\
\hline & $\overline{\mathrm{BOPO}}$ & CAR & LDR & ROA \\
\hline $\mathrm{N}$ & 135 & 135 & 135 & 135 \\
\hline Normal Mean & 86.188 & 21.332 & 87.203 & 1.335 \\
\hline $\begin{array}{ll}\text { Paramet } & \text { Std. } \\
\mathrm{e} & \text { Deviation } \\
-\mathrm{rs}^{\mathrm{a}, \mathrm{b}} & \text { Devila }\end{array}$ & 10.448 & 5.871 & 15.062 & 1.121 \\
\hline $\begin{array}{l}\text { Kolmogorov- } \\
\text { Smirnov Z }\end{array}$ & .649 & 1.264 & 1.186 & .952 \\
\hline $\begin{array}{l}\text { Asymp. Sig. } \\
\text { tailed) }\end{array}$ & $2-.793$ & .082 & .120 & .325 \\
\hline
\end{tabular}

Sumber : Hasil Pengolahan SPSS, Peneliti (2021)

Nilai Asymp. Sig untuk BOPO adalah 0,793 yang artinya lebih besar 0,05, kemudian nilai Asymp. Sig untuk CAR adalah 0,082 yang berarti lebih besar dari 0,05. Nilai Asmpy. Sig untuk LDR adalah 0,120 yang artinya lebih besar dari 0,05 dan nilai Asymp. Sig untuk ROA adalah 0,325 yaitu lebih besar dari 0,05. Berdasarkan data yang didapatkan dengan nilai Asmpy. Sig BOPO, CAR, LDR dan ROA yang berada diatas angka 0,05, maka dinyatakan bahwa data yang digunakan berdistribusi normal.

Uji multikoleniaritas dilakukan untuk menghindari timbulnya kebiasan dalam pengambilan keputusan terkait pengaruh variabel independen secara mandiri terhadap variabel dependen serta untuk mengetahui apakah terdapat kesamaan antara variabel independen dalam suatu model. 
Tabel 4.

Hasil Uji multikoleniaritas

\begin{tabular}{|c|c|c|}
\hline \multicolumn{3}{|c|}{ Coefficients $^{\mathrm{a}}$} \\
\hline & \multicolumn{2}{|c|}{ Collinearity Statistics } \\
\hline & Tolerance & VIF \\
\hline (Constant) & & \\
\hline BOPO & .945 & 1.059 \\
\hline CAR & .995 & 1.005 \\
\hline LDR & .941 & 1.063 \\
\hline
\end{tabular}

a. Dependent Variable: ROA

Sumber : Hasil Pengolahan SPSS, Peneliti (2021)

Berdasarkan data pada Tabel 4., hasil uji multikoleniaritas didapatkan bahwa nilai VIF variabel BOPO, CAR dan LDR berada diantara angka 1 hingga 10, sehingga disimpulkan bahwa data tidak terjadi multikoleniaritas.

Tabel 5.

Hasil uji Autokolerasi

\begin{tabular}{|c|c|c|c|c|}
\hline \multicolumn{5}{|c|}{ Model Summary $^{b}$} \\
\hline Model & $\mathrm{R}$ & R Square & $\begin{array}{l}\text { Adjusted } \\
\text { R Square }\end{array}$ & $\begin{array}{l}\text { Durbin- } \\
\text { Watson }\end{array}$ \\
\hline & $.801^{\mathrm{a}}$ & .641 & .633 & 1.898 \\
\hline
\end{tabular}

a. Predictors: (Constant), LDR, CAR, BOPO

b. Dependent Variable: ROA

Sumber : Hasil Pengolahan SPSS, Peneliti (2021)

Pengujian autokolerasi ditujukan untuk mengetahui apakah antara variabel penggangu dengan variabel sebelumnya terdapat kolerasi. Untuk mengetahui autokolerasi pada data, maka digunakan nilai Durbin Watson dengan membandingkan tabel DW ( $d l$ dan $d u$ ). Jika $d u$ lebih kecil dari d hitung, dan d hitung lebih kecil dari 4-du maka data tidak mengalami autokolerasi.

Berdasarkan hasil pengujian autokolerasi didapatkan nilai Durbin Watson sebesar 1,898. Dengan jumlah sampel sebanyak 135 dan jumlah variabel independen sebanyak 3, maka didapatkan nilai dU untuk $\mathrm{k}=3, \mathrm{n}=135$ adalah 1,7645. Sehingga du $<$ DW $<4$-du, 1,7645 < 1,898< 2,3262, artinya data tidak terjadi gejala autokolerasi.

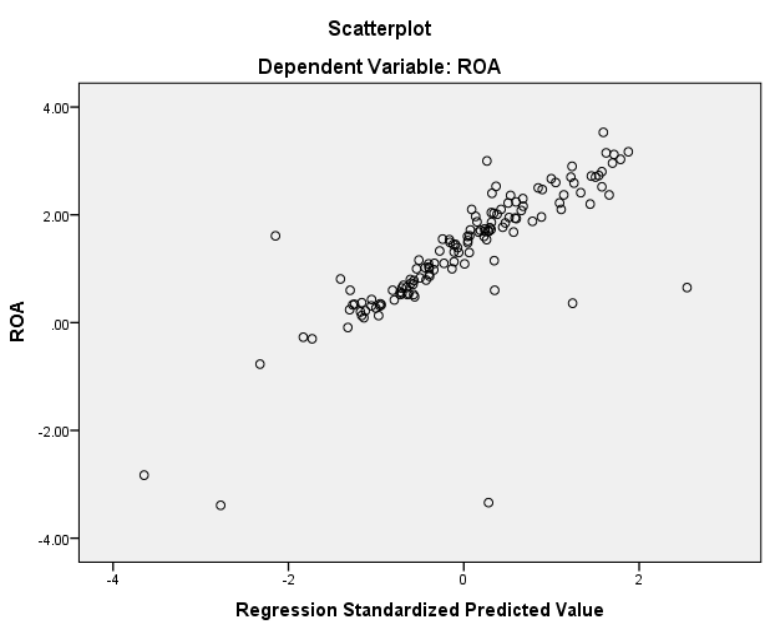

Sumber : output SPSS v.21, data diolah peneliti (2021)

Gambar 2.

Hasil uji Heteroskedastisitas

Pengujian heteroskedastisitas ditujukan untuk menguji disimilaritas antara varians residual dalam suatu periode pengamatan dengan periode pengamatan lainnya. Untuk mengetahui ada atau tidaknya gejala heteroskedastisitas dalam suatu model maka dapat dilihat berdasarkan gambar scatterplot. Berdasarkan Gambar 2, diketahui bahwa data menyebar diatas, dibawah dan sekitar angka 0 (nol). Titik-titik data yang menyebar tidak menciptakan suatu pola mengombak yang memencar kemudian menyempit dan melebar kembali, sehingga dapat disimpulkan bahwa tidak terjadi heteroskedastisitas pada data.

Tabel 6. 
Hasil Uji Regresi Linear Berganda

\begin{tabular}{|c|c|c|c|c|c|c|}
\hline \multicolumn{7}{|c|}{ Coefficients $^{\mathrm{a}}$} \\
\hline & Model & \multicolumn{2}{|c|}{$\begin{array}{l}\text { Unstandar- } \\
\text { dized } \\
\text { Coefficients }\end{array}$} & \multirow{2}{*}{$\begin{array}{r}\begin{array}{c}\text { Standar- } \\
\text { dized } \\
\text { Coeffi- } \\
\text { cients }\end{array} \\
\text { Beta }\end{array}$} & \multirow[t]{2}{*}{$\mathrm{t}$} & \multirow[t]{2}{*}{ Sig. } \\
\hline & & B & $\begin{array}{c}\text { Std. } \\
\text { Error }\end{array}$ & & & \\
\hline \multirow{4}{*}{1} & $\begin{array}{c}\text { (Cons- } \\
\tan t)\end{array}$ & 9.338 & .719 & & 12.979 & .000 \\
\hline & BOPO & -.087 & .006 & -.811 & -15.064 & .000 \\
\hline & CAR & -.007 & .010 & -.035 & -.666 & .506 \\
\hline & LDR & -.004 & .004 & -.055 & -1.013 & .313 \\
\hline
\end{tabular}

a. Dependent Variable: ROA

\section{Sumber : Hasil Pengolahan SPSS, Peneliti (2021)}

Berdasarkan hasil pengujian regresi linear berganda yang ditunjukkan oleh Tabel 6. maka didapatkan hasil persamaan pengujian hipotesis sebagai berikut : $\mathrm{Y}(\mathrm{ROA})=9,338-0,087 \mathrm{X}_{1}-0,007 \mathrm{X}_{2}-$

$$
0,004 \mathrm{X}_{3}+\mathrm{e}
$$

Berdasarkan hasil persamaan yang didapatkan, maka dapat dijelaskan bahwa nilai konstanta $\left(\mathrm{B}_{0}\right)$ adalah sebesar 9,338, artinya apabila tidak ada perubahan pada variabel BOPO, CAR dan LDR maka ROA tetap sebesar 9,338. Koefisien regresi BOPO $\left(\mathrm{X}_{1}\right)$ memiliki nilai negatif yaitu sebesar 0,087 , artinya ada hubungan tidak searah antara BOPO dengan ROA dan apabila terjadi peningkatan pada BOPO sebesar 1 maka akan menimbulkan penurunan pada ROA sebesar 0,087 . Hal serupa terjadi pada koefisien regresi CAR $\left(\mathrm{X}_{2}\right)$ yang memiliki nilai negatif yaitu sebesar -0,007, artinya terdapat hubungan tidak searah antara CAR dengan ROA dan apabila terdapat peningkatan sebesar 1 pada CAR maka akan menyebabkan penurunan pada ROA sebesar 0,007.
Koefisien regresi untuk variabel LDR $\left(\mathrm{X}_{3}\right)$ memiliki nilai negatif yaitu sebesar $-0,004$, artinya terdapat hubungan tidak searah antara LDR dengan ROA dan apabila terjadi peningkatan pada LDR sebesar 1 maka akan menyebabkan penurunan pada ROA sebesar 0,004 .

Pengujian hipotesis ditujukan untuk mengetahui apakah terdapat pengaruh antara variabel independen terhadap variabel dependen serta untuk membuktikan hipotesis yang telah dirumuskan ditolak atau diterima. Uji parsial (t-test) ditujukan untuk mengetahui ada tidaknya pengaruh variabel independen secara parsial terhadap variabel dependen yang dapat dilihat dari nilai thitung terhadap $t$ tabel menggunakan uji 2 sisi, yaitu apabila $-t_{\text {tabel }}<t_{\text {hitung }}<t_{\text {tabel }}$, maka Ho diterima, sebaliknya apabila $-\mathrm{t}_{\text {hitung }}<-\mathrm{t}_{\text {tabel }}$ atau $t_{\text {hitung }}>t_{\text {tabel}}$, maka Ho ditolak. Dalam penelitian ini diketahui $\mathrm{n}$ sebanyak 135, pada tingkat kesalahan $(\alpha) \quad 0,05$ dengan menggunakan uji 2 sisi, didapatkan nilai tabel $(\mathrm{df}=135-1 ; 0,025)$ sebesar 1,977 .

Hipotesis pertama menyatakan bahwa pada hasil pengujian Tabel 6. diketahui nilai thitung BOPO sebesar 15,064 > 1,977, maka Ho ditolak dan Ha diterima, dengan tingkat signifikan $0,000<0,05$ dan koefisien regresi bernilai $-0,087$ artinya terdapat pengaruh negatif secara signifikan antara variabel BOPO terhadap variabel ROA secara parsial. Untuk pernyataan $\mathrm{H}_{1}$ diterima. Hasil pengujian ini sejalan dengan penelitian Pradnyawati \& Widhiastuti (2020) yang menyatakan bahwa BOPO memiliki pengaruh negatif dan signifikan terhadap profitabilitas. Pernyataan ini didukung pula oleh pernyataan Dewi (2018); Rusmini \& Adiandari (2020) 
Pengaruh BOPO, CAR dan LDR Terhadap...

Aditya Permana Magdalena \& Nesti Hapsari

dalam penelitiannya yang menyatakan bahwa BOPO memiliki pengaruh negatif dan signifikan terhadap profitabilitas.

Hipotesis kedua menyatakan berdasarkan hasil pengujian didapatkan nilai $t_{\text {hitung }}$ CAR adalah sebesar 0,666 < 1,997, maka angka tersebut menunjukkan Ho diterima dan $\mathrm{Ha}$ ditolak, dengan tingkat signifikan 0,506>0,05 artinya CAR tidak memiliki pengaruh terhadap ROA. Untuk pernyataan $\mathrm{H}_{2}$ ditolak. Hasil penelitian ini sejalan dengan penelitian yang dilakukan oleh Pandoyo \& Samsudin (2020) yang menyatakan bahwa CAR tidak memiliki pengaruh terhadap profitabilitas. Pernyataan ini didukung pula dengan penelitian yang dilakukan oleh Marwansyah \& Setyaningsih (2018); Azmy dkk., (2019) yang menyatakan bahwa CAR tidak berpengaruh terhadap profitabilitas.

Hipotesis ketiga menyatakan bahwa berdasarkan hasil pengujian diketahui nilai

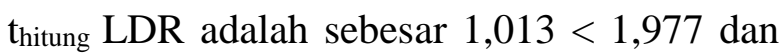
nilai signifikan sebesar $0,313>0,05$, artinya LDR tidak memiliki pengaruh terhadap ROA. Untuk pernyataan $\mathrm{H}_{3}$ ditolak. Hal ini sejalan dengan hasil penelitian yang dilakukan oleh Fajari \& Sunarto (2017): Pandoyo \& Samsudin (2020) yang menyatakan bahwa LDR tidak berpengaruh terhadap profitabilitas.

Berdasarkan hasil pengujian analisis regresi berganda dan analisis terhadap uji parsial, maka didapatkan bahwa BOPO memiliki pengaruh negatif dan signifikan terhadap ROA, artinya apabila BOPO mengalami kenaikan maka ROA akan mengalami penurunan. Sehingga manajemen perusahaan perlu lebih memperhatikan kembali pengelolaan operasional perusahaannya, apabila perusahaan dapat menurunkan nilai BOPO maka perusahaan akan mendapatkan penambahan nilai profitabilitas perusahaan. Variabel CAR dan LDR didapatkan tidak memiliki pengaruh terhadap ROA, artinya setiap kenaikan yang terjadi pada CAR dan LDR tidak memengaruhi nilai ROA. Meskipun demikian, manajemen perusahaan tetap harus memperhatikan nilai CAR dan LDR perusahaan agar tidak melewati batas aman yang telah ditetapkan oleh peraturan BI agar perusahaan dapat mempertahankan keberlangsungan perusahaan.

Uji simultan (f-test) dilakukan untuk mengetahui apakah variabel independen secara bersama-sama berpengaruh terhadap variabel dependen. Untuk mengetahui pengaruh variabel independen terhadap variabel dependen secara simultan atau bersama-sama, maka digunakan kriteria berikut: apabila nilai $\mathrm{F}_{\text {hitung }}<\mathrm{F}_{\text {tabel }}$ maka Ho diterima dan apabila $F_{\text {hitung }}>\mathrm{F}_{\text {tabel }}$ maka Ho ditolak. Dengan menggunakan tingkat signifikan $(\alpha)$ 0,05 maka df1 $(\mathrm{k}-1)=3-1=2$, df2 $(n-k-1)=135-3-1=131$ sehingga didapatkan $F_{\text {tabel }}$ sebesar 2,67.

Tabel 7.

Hasil Uji simultan (F-test)

\begin{tabular}{clllll}
\hline \multicolumn{6}{c}{ ANOVA $^{\text {a }}$} \\
\hline Model & & df & $\begin{array}{c}\text { Mean } \\
\text { Square }\end{array}$ & F & Sig. \\
\hline \multirow{2}{*}{1} & Regression & 3 & 36.001 & 77.962 & $.000^{\mathrm{b}}$ \\
& Residual & 131 & .462 & & \\
& Total & 134 & & & \\
\hline
\end{tabular}

a. Dependent Variable: ROA

b. Predictors: (Constant), LDR, CAR, BOPO

Sumber : Hasil Pengolahan SPSS, Peneliti (2021) 
Berdasarkan hasil pengujian yang ditunjukkan oleh Tabel 7. Diperoleh nilai $F_{\text {hitung }}$ sebesar 77,962 > 2,67, maka Ho ditolak dan Ha diterima, sehingga dapat diketahui bahwa secara simultan terdapat pengaruh antara BOPO, CAR dan LDR terhadap ROA. Untuk pernyataan $\mathrm{H}_{4}$ diterima.

Tabel 8.

Hasil uji koefisien determinasi $\left(\mathbf{R}^{2}\right)$

\begin{tabular}{ccccc}
\hline \multicolumn{4}{c}{ Model Summary $^{\mathbf{b}}$} \\
\hline Model & $\mathrm{R}$ & R Square & $\begin{array}{l}\text { Adjusted } \\
\text { Square }\end{array}$ & $\mathrm{R}$ \\
\hline 1 & $.801^{\mathrm{a}}$ & .641 & .633 \\
\hline
\end{tabular}

a. Predictors: (Constant), LDR, CAR, BOPO

b. Dependent Variable: ROA

Sumber : Hasil Pengolahan SPSS, Peneliti (2021)

Pengujian koefisien determinasi ditujukan untuk mengetahui seberapa besar variabel dependen dipengaruhi oleh variabel independen yang diteliti. Nilai koefisien yang ditunjukkan $\mathrm{R}$ square adalah sebesar 0,641 atau $64,1 \%$. Artinya variabel dependen, yaitu ROA dipengaruhi oleh variabel independennya, yaitu BOPO, CAR dan LDR sebesar $64,1 \%$ dan sisanya sebesar $35,9 \%$ ROA dipengaruhi oleh variabel lain yang belum diteliti dalam penelitian ini.

\section{SIMPULAN DAN SARAN}

Berdasarkan hasil penelitian dan analisis yang telah dikemukakan, maka didapatkan bahwa BOPO memiliki pengaruh negatif dan signifikan terhadap ROA, CAR tidak memiliki pengaruh terhadap ROA dan LDR tidak memiliki pengaruh terhadap ROA. Profitabilitas perusahaan tidak selalu dipengaruhi oleh faktor modal dan kredit. Peningkatan BOPO dan LDR perlu menjadi perhatian bagi pihak manajemen agar dapat melakukan pengelolaan keuangan bank dengan lebih baik. Jika pengelolaan operasional perusahaan yang kurang efektif akan menyebabkan profitabilitas perusahaan menurun dan apabila tingkat penyaluran kredit mengalami peningkatan yang melewati batas ketentuan maka perlu dilakukan pengawasan lebih lanjut. Kecukupan modal perusahaan tentu perlu mendapat perhatian dari manajemen perusahaan, jika kecukupan modal perusahaan baik maka perusahaan dapat meningkatkan kredit usahanya. Penelitian ini dapat pula digunakan sebagai pendukung keputusan bagi investor ketika akan melakukan investasi.

Bagi peneliti berikutnya yang akan melakukan penelitian serupa, disarankan untuk memambahkan variabel penelitian serta waktu penelitian agar diperoleh hasil yang lebih maksimal dan akurat.

\section{REFERENSI}

Anggari, N. L. S., \& Dana, I. M. (2020). The Effect of Capital Adequacy Ratio, Third Party Funds, Loan to Deposit Ratio, Bank Size on Profitability in Banking Companies on IDX. American Journal of Humanities and Social Sciences Research (AJHSSR), 4(12), 334-338. https://www.ajhssr.com/wpcontent/uploads/2020/12/ZP20412334338.pdf

Azmy, A., Febriansyah, I., \& Munir, A. (2019). The Effect of Financial Performance Ratios on Conventional Bank Profitability in Indonesia Stock Exchange. Ekuilibrium : Jurnal Ilmiah Bidang Ilmu Ekonomi, 14(2), 84. https://doi.org/10.24269/ekuilibrium.v14i2.15 68

Dewi, A. S. (2018). Pengaruh CAR, BOPO, NPL, NIM, dan LDR terhadap ROA Pada 
Pengaruh BOPO, CAR dan LDR Terhadap...

Aditya Permana Magdalena \& Nesti Hapsari

Perusahaan di Sektor Perbankan yang Terdaftar di BEI Periode 2012-2016. Jurnal Pundi, 1(3), 223-236. https://doi.org/10.31575/jp.v1i3.55

Fajari, S., \& Sunarto. (2017). Pengaruh CAR, LDR, NPL, BOPO terhadap Profitabilitas Bank (Studi Kasus Perusahaan Perbankan yang Tercatat di Bursa Efek Indonesia Periode Tahun 2011 sampai 2015). Prosiding Seminar Nasional Multi Disiplin Ilmu \& Call for Papers UNISBANK Ke-3, 3(Sendi_U 3), 853862.

https://www.unisbank.ac.id/ojs/index.php/sen di_u/article/view/5035

Febrianti, S., \& Ladinus, L. (2019). Analisis Rasio Keuangan Dalam Memprediksi Tingkat Profitabilitas Bank Umum Konvensional (Studi Pada Bank Umum Yang Listing di BEI Periode 2012-2016). Prosiding Seminar Nasional Pakar Ke-2, 2-29. https://trijurnal.lemlit.trisakti.ac.id/pakar/articl e/view/4305

Hartini, T. (2016). Pengaruh Biaya Operasional dan Pendapatan Operasional (BOPO) Terhadap Profitabilitas Bank Syariah di Indonesia. IFinance: A Research Journal on Islamic Finance, 2(1), 20-34. http://jurnal.radenfatah.ac.id/index.php/IFinance/article/view/1007

Ikatan Akuntan Indonesia. (2012). Standar Akuntansi Keuangan. Jakarta:Salemba Empat.

Ikatan Bankir Indonesia. (2016). Manajemen Kesehatan Bank Berbasis Risiko. Jakarta: Gramedia Pustaka Utama.

Kasmir. (2014). Lembaga Keuangan Bank \& Lainnya:Edisi Revisi. Jakarta : PT Raja Grafindo Persada.

Korri, N. T. L., \& Baskara, I. G. K. (2019). Pengaruh Capital Adequacy Ratio, Non Performing Loan, Bopo dan Loan To Deposit Ratio Terhadap Profitabilitas. E-Jurnal Manajemen Universitas Udayana, 8(11), 6577. https://doi.org/10.24843/ejmunud.2019.v08.i1 1.p10

Marwansyah, S., \& Setyaningsih, E. D. (2018). Pengaruh Kinerja Perbankan Terhadap Rasio Profitabilitas Pada Bank BUMN. Jurnal Akuntansi, Ekonomi Dan Manajemen Bisnis, 6(1), 35-42. https://doi.org/10.30871/jaemb. v6i1.640

Munawir, S. (2014). Analisa laporan keuangan. Yogyakarta:Liberty

Nuryanto, U. W., Salam, A. F., Sari, R. P., \& Suleman,
D. (2020). Pengaruh Rasio Kecukupan Modal, Likuiditas, Risiko Kredit dan Efisiensi Biaya Terhadap Profitabilitas Pada Bank Go Public. Moneter - Jurnal Akuntansi Dan Keuangan, $7(1)$, 1-9. https://doi.org/10.31294/moneter.v7i1.6777

PJOK Nomor 15/POJK.03/2017. Penetapan Status dan Tindak Lanjut Pengawasan Bank Umum. In Otoritas Jasa Keuangan.

Pandoyo \& Samsudin. (2020). Influence of CAR, LDR, NPL and Bopo on ROA on Commercial Banks Listed on the Indonesia Stock Exchange in 2010-2016. Journal of Economics, Finance and Management Studies, 03(12), 296-302. https://doi.org/10.47191/jefms/v3-i12-11

Peling, I. A. A., \& Sedana, I. B. P. (2018). Pengaruh LDR, NPL, dan BOPO Terhadap Profitabilitas Pada PT. BPD Bali Periode Tahun 2009-2016. E-Jurnal Manajemen Universitas Udayana, 7(6), 2999. https://doi.org/10.24843/EJMUNUD.2018.v0 7.i06.p06

Pinasti, W. F., \& Mustikawati, RR. I. (2018). Pengaruh CAR, BOPO, NPL, NIM dan LDR Terhadap Profitabilitas Bank Umum Periode 20112015. Nominal, Barometer Riset Akuntansi Dan Manajemen, 2(1). https://doi.org/10.21831/nominal.v7i1.19365

Pradnyawati, S. O., \& Widhiastuti, N. L. P. (2020). The Effects of NIM, LDR and BOPO on Balinese People'S Credit Bank (BPR) Profitability of Tabanan. American Journal of Humanities and Social Sciences Research, 4(11), 196-203. https://www.ajhssr.com/wpcontent/uploads/2020/11/X20411196203.pdf

Ramli, R. R. (2020). Enam Bulan Pandemi, Bagaimana Kondisi Perbankan Nasional?. Retrieved from:https://money.kompas.com/read/2020/09 /17/153400226/enam-bulan-pandemibagaimana-kondisi-perbankan-nasional?page $=$ all

Rusmini, N. M., \& Adiandari, A. M. (2020). Effect of Loan to Deposit Ratio (LDR) and BOPO on Profitability on PT BPR Bali Ambassador for The Year 2014-2018. Neraca: Jurnal Akuntansi Terapan, 1(2), 84-93. https://doi.org/10.31334/neraca.v1i2.858

Sanusi, A. (2011). Metodologi penelitian bisnis. Jakarta: Salemba Empat.

Septiani, R., \& Lestari, P. V. (2016). Pengaruh NPL dan LDR Terhadap Profitabilitas Dengan CAR Sebagai Variabel Mediasi Pada PT BPR 
Pasarbaya Kuta. E-Jurnal Manajemen Unud, 5(1), 293-324. https://ojs.unud.ac.id/index.php/Manajemen/ar ticle/view/15907

Sugiyono. (2017). Metode Penelitian Bisnis: Pendekatan Kuantitatif, Kualitatif, Kombinasi, dan $R \& D$. Penerbit CV. Alfabeta: Bandung.

Warsa, M., \& Mustanda, I. (2016). Pengaruh CAR, LDR dan NPL terhadap ROA pada sektor Perbankan di Bursa Efek Indonesia. E-Jurnal Manajemen, $5(5)$. https://ojs.unud.ac.id/index.php/Manajemen/ar ticle/view/18244

Wijaya, E., \& Tiyas, A. W. (2016). Analisis Pengaruh Kecukupan Modal, Likuditas, Risiko Kredit dan Efisiensi Biaya Terhadap Profitabilitas Bank Umum. Jurnal Ekonomi, Manajemen Dan Perbankan, 2(3), 99-109. http://journal.ibs.ac.id/index.php/JEMP/article /view/108

Wijaya, T. (2013). Metodologi Penelitian Ekonomi dan Bisnis Teori dan Praktik. Yogyakarta: Graha Ilmu. 